\title{
Changes of geoacoustic emission directivity at «Mikizha» site associated with earthquakes in Kamchatka
}

\author{
Yuriy Marapulets ${ }^{1, \star}$, Alexandra Solodchuk ${ }^{1, \star \star}$, and Albert Shcherbina ${ }^{1, \star \star \star}$ \\ ${ }^{1}$ Institute of Cosmophysical Research and Radio Wave Propagation FEB RAS, Russia, 684034, Kamchatka \\ region, Elizovskiy district, Paratunka, Mirnaya str., 7
}

\begin{abstract}
To investigate high frequency geoacoustic emission, a receiving system based on a compound vector receiver was installed in Kamchatka. It allows the authors to determine the direction of sound wave arrival. In the result of data analysis for the period from August 2008 to January 2016, it was determined that anomalies of geoacoustic emission directivity occur during the majority of the earthquakes with $K_{s}>9.0$ in the South of Kamchatka.
\end{abstract}

\section{Introduction}

Investigations of geoacoustic emission in the frequency range from $0.1 \mathrm{~Hz}$ to $10 \mathrm{kHz}$ are carried out at the Institute of Cosmophysical Research and Radio Wave Propagation, Kamchatka peninsula. Analysis of geoacoustic signal shows that it consists of a series of relaxation pulses of different amplitude and duration with shock excitation and the carrier frequency from units to tens and more kilohertz. The pulse repetition frequency (acoustic activity $\Omega(t)$ ) is determined by rock deformations and may vary within a wide range, from single signals on a time interval of several of seconds during calm periods to tens and even hundreds per a second during intensification of plastic process, in particular before earthquakes. This acoustic effect manifests itself the most vividly in the kilohertz frequency range [1], [2]. Some cases have been registered when acoustic activity increased suddenly some days before an earthquake. Clear maxima were observed on the diagram of its azimuthal distribution [3], [4]. Thus, it is reasonable to analyze the changes of high-frequency geoacoustic emission directivity during earthquake preparation in Kamchatka.

\section{Methods of investigations}

Investigations of the directivity properties of high-frequency geoacoustic emission are carried out by a hardware-software complex installed at "Mikizha" observation site of IKIR FEB RAS. Registration of geoacoustic data and estimations of a sound wave arrival direction are realized by a receiving hydroacoustic system constructed on the base of a combined receiver manufactured by ZAO "Geoakustika" and mounted by the bottom of a natural lake [5].

\footnotetext{
^e-mail: marpl@ikir.ru

$\star \star$ e-mail: aleksandra@ikir.ru

$\star \star \star$ e-mail: albert@ikir.ru
} 
To analyze the changes of geoacoustic emission directivity during earthquakes, we chose 4 groups of earthquakes from the seismic catalogue of Kamchatka Branch of Geophysical Service RAS. The earthquakes occurred during the period from August 2008 to January 2016 with the energy classes of $9.0<K_{s} \leq 10,10<K_{s} \leq 11,11<K_{s} \leq 12$ and $K_{s}>12$ and at the epicentral distances of $R \leq 120 \mathrm{~km}$, $R \leq 190 \mathrm{~km}, R \leq 240 \mathrm{~km}$ and $R \leq 350 \mathrm{~km}$, respectively. Such distances were chosen taking into account the results of investigations [6] and corrected based on [7]. The earthquakes which occurred from February 10 to July 09, 2013 were excluded from the analysis due to the absence of geoacoustic data during the mentioned period. Thus, 276 seismic events were chosen.

During calm weather conditions (weakly changing pressure, absence of precipitation and wind of more than $6 \mathrm{~m} / \mathrm{s}$ ) within the interval of \pm 5 days close to an earthquake, acoustic activity $\Omega(t)$ and its azimuthal distribution $D(\alpha, t)$ were under consideration. It was believed that anomalies associated with a seismic event are observed in the directivity of geoacoustic emission when in the time interval mentioned above, the pulse repetition frequency and its distribution in one or in several directions exceed the values of the corresponding background levels by 2.5 and more times. Background levels are chosen according to the results of preliminary analysis of long-term observation series of acoustic activity.

\section{Results of investigation and discussion}

In the result of the analysis it was ascertained that there are anomalies in geoacoustic emission directivity which occur close to 219 earthquakes out of 276 (79\%). Anomalies which could be associated with several seismic events were not included into further consideration because it was difficult to determine the impact of each event into the investigated effects. Fig. 1 shows an example of such an anomaly.

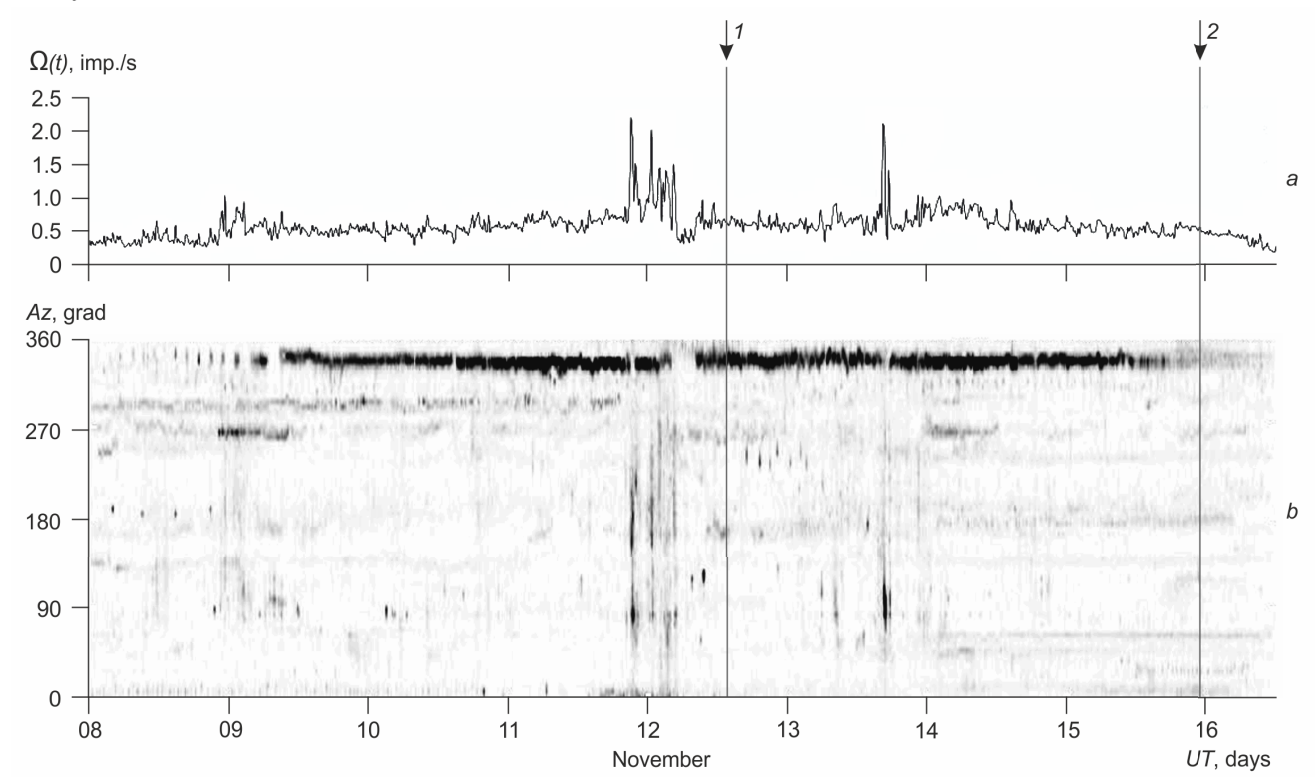

Figure 1. Acoustic activity $\Omega(t)(a)$ and its azimuthal distribution $D(\alpha, t)(b)$, registered close to the earthquakes on 12.11.2015 at $13: 54 \mathrm{UT}\left(51.39^{\circ} \mathrm{N}, 158.90^{\circ} \mathrm{E}\right)$ with $K_{s}=12.3$ and $R=180 \mathrm{~km}(1)$ and on 15.11.2015 at 23:17 UT $\left(52.39^{\circ} \mathrm{N}, 159.36^{\circ} \mathrm{E}\right)$ with $K_{s}=11.7$ and $R=100 \mathrm{~km}(2) . A z$ - azimuth. Arrows continued as lines indicate the times of earthquakes. 
Thus, anomalies of directivity observed close only to one earthquake were analyzed. They were registered in 73 cases. It was ascertained that anomaly duration varies within the range from 10 to 60 hours (Fig. $2 a$ ). The increased activity is mainly registered from the directions corresponding to the amithuths of $50^{\circ}, 155^{\circ}, 225^{\circ}, 330^{\circ}$ (Fig. $2 b$ ). Similar azimuths were earlier detected during the investigations of geoacoustic emission directivity [4].
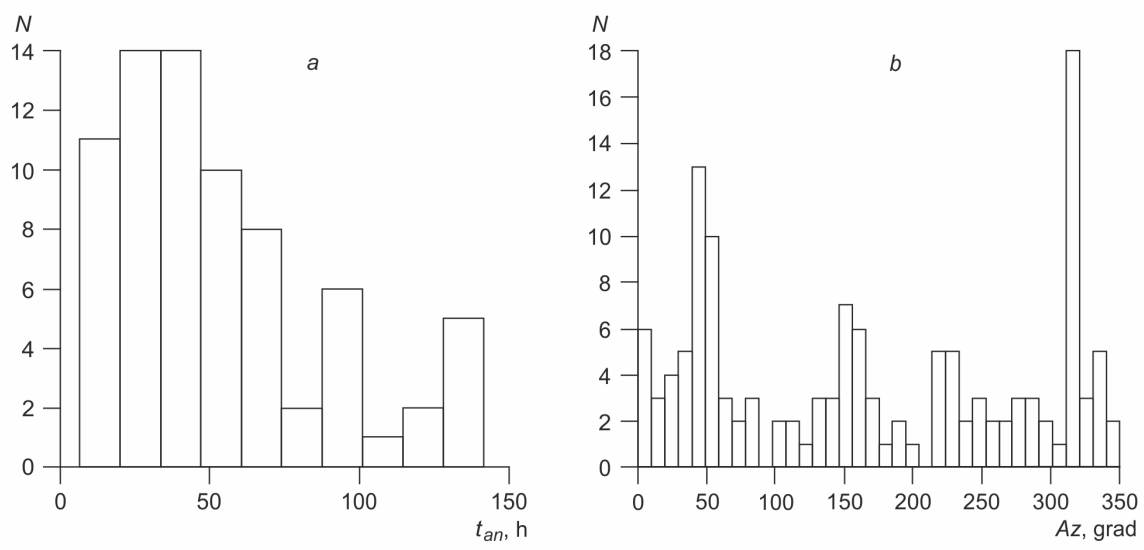

Figure 2. Histograms of duration $t_{a n}(a)$ and of azimuths $A z(b)$ of geoacoustic emission anomalies. $N-$ the number of anomalies.

Analysis of the duration of geoacoustic emission directivity anomalies close to seismic events showed that they occur 10-30 $\mathrm{h}$ before earthquakes and last for 6-30 $\mathrm{h}$ after them in most cases.

Fig. 3 illustrates the dependences of anomaly duration on earthquake class $(a)$ and on epicentral distance $(b)$. Correlation coefficients of these values are -0.04 and 0.01 at the significance levels of 0.7 and 0.9 , respectively. Thus, we have not discovered any relation between the parameters under investigation.
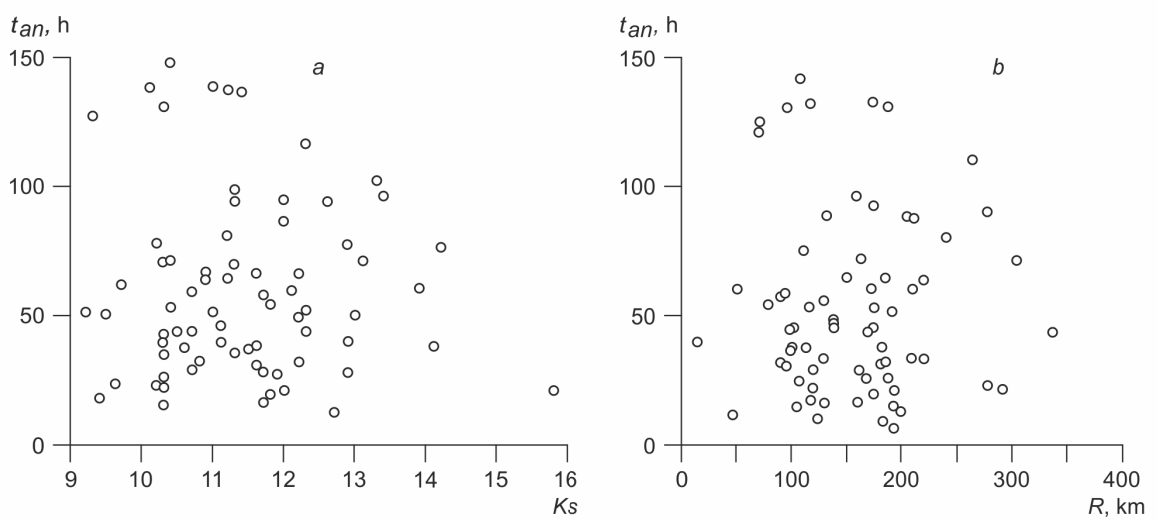

Figure 3. Dependences of anomaly duration $t_{a n}$ on earthquake class $K_{s}(a)$ and epicentral distance $R(b)$. 
As an example, Fib. 4 and Fig. 5 show anomalies of geoacoustic emission directivity associated with earthquakes.

Fig. 4 illustrates an anomaly registered $30 \mathrm{~h}$ before the earthquake with the energy class of $K_{s}=10.3$, which occurred 17.12 .2012 at $03: 10 \mathrm{UT}\left(51.87^{\circ} \mathrm{N}, 159.12^{\circ} \mathrm{E}\right)$ at the epicentral distance of $R=140 \mathrm{~km}$ ( 1 on the graph), and ended in $17 \mathrm{~h}$ after it (anomaly duration was $47 \mathrm{~h}$ ). On the graph of integral activity (Fig. 4a) sharp increase of geoacoustic pulse repetition frequency is observed (with background level increase by more than 4 times). Activations of the directions in the range of $40^{\circ}-50^{\circ}$ correspond to it (Fig. 4b).

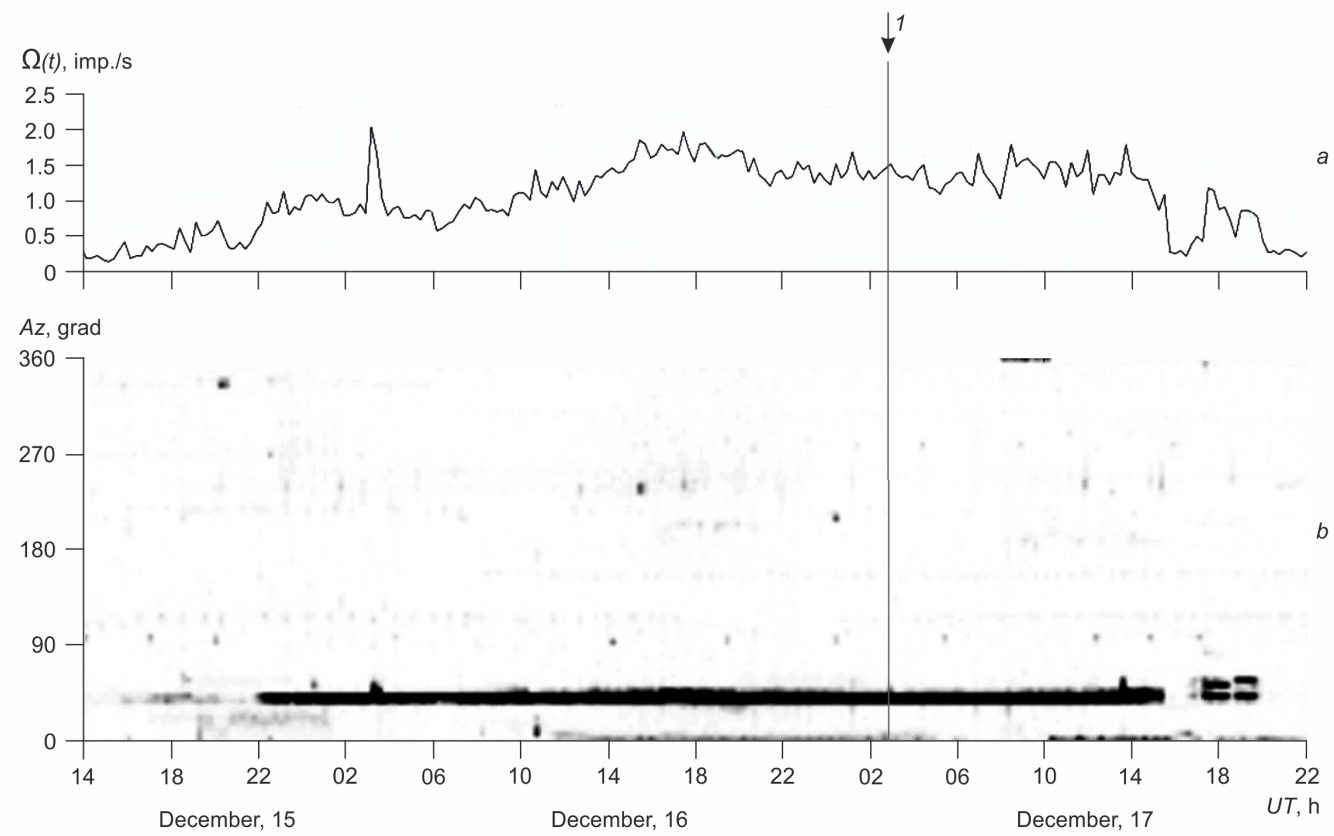

Figure 4. Acoustic activity $\Omega(t)(a)$ and its azimuthal distribution $D(\alpha, t)(b)$ close to the earthquake with the energy class of $K_{s}=10.3(1)$. $A z$ - azimuth. Arrows continued as lines indicate the times of earthquakes.

Fig. 5 shows anomalies of geoacoustic emission directivity associated with the earthquakes with the energy class of $K_{s}=15.7$ which occurred on 30.01 .2016 at $03: 25$ UT $\left(53.85^{\circ} \mathrm{N}, 159.03^{\circ} \mathrm{E}\right)$ at the epicentral distance of $R=110 \mathrm{~km} \quad(1$ on the graph). Its strongest aftershocks were registered on 30.01 .2016 at $03: 42 \mathrm{UT}\left(53.75^{\circ} \mathrm{N}, 159.07^{\circ} \mathrm{E}\right)$ with $K_{s}=11.6$ and $R=100 \mathrm{~km}$ ( 2 on the graph) and at $06: 53 \mathrm{UT}\left(53.87^{\circ} \mathrm{N}, 159.21^{\circ} \mathrm{E}\right)$ with $K_{s}=10.5$ and $R=120 \mathrm{~km}$ ( 3 on the graph). The anomaly with the direction range of $330^{\circ}-350^{\circ}$ (Fig. $5 b$ ), during which the exceedance of the acoustic activity background level by more than 5 times was observed (Fig. $5 a$ ), began $15 \mathrm{~h}$ before the earthquake with $K_{s}=15.7$ and ended about 30 minutes before it. Almost simultaneously with it, a less increase of activity was registered in azimuth $280^{\circ}$ (Fig. $5 \mathrm{~b}$ ). It continued after the earthquake and was likely associated with aftershocks. 


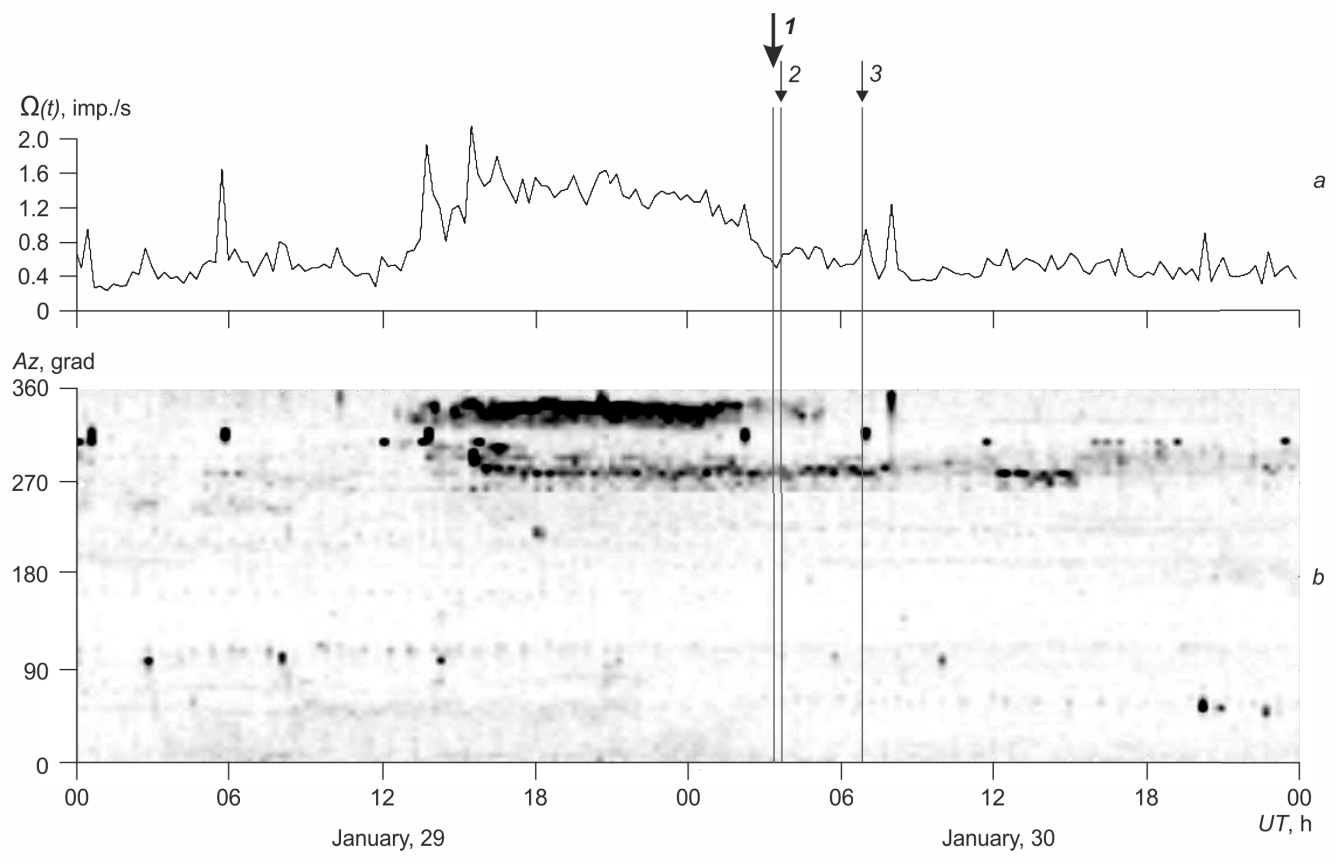

Figure 5. Acoustic activity $\Omega(t)$ ( $a$ ) and its azimuthal distribution $D(\alpha, t)(b)$ close to the earthquake with $K_{s}=15.7$ (1) and its aftershocks (2 and 3). $A z$ - azimuth. Arrows continued as lines indicate the times of earthquakes.

\section{Conclusions}

Thus, in the result of the analysis of the high-frequency geoacoustic emission directivity change, we determined anomalies associated with earthquakes. They appear as sharp increases of geoacoustic pulse repetition frequency in some directions. Such effects occur 10-30 h before earthquakes and last for $6-30 \mathrm{~h}$ after it in most cases.

\section{References}

[1] Dolgikh G. I., et al. Doklady Earth Sciences 413:2, 281-285 (2007)

[2] Marapulets Yu. V., Shevtsov B. M., Mezomasshtabnaya akusticheskaya emissiya [Mesoscale acoustic emission] (Dal'nauka, Vladivostok, 2012) 126 p.

[3] Shevtsov B. M., Marapulets Yu. V., Shcherbina A. O. Doklady Earth Sciences 430:1, 67-70 (2010)

[4] Marapulets Yu. V., Shcherbina A. O. Solnechno-zemnye svyazi i fizika predvestnikov zemletryaseniy, VI mezhdunarodnaya konferentsiya, ed. Shevtsov B. M., sb. dokl. , 316-319 (2013)

[5] Marapulets Yu. V., Shcherbina A. O. Pribory 9(183), 14-19 (2015)

[6] Kuptsov A. V. Izvestiya. Physics of the Solid Earth 41:10, 825-831, (2005)

[7] Dobrovol'skiy I. P. Mekhanika podgotovki tektonicheskogo zemletryaseniya [Mechanics of tectonic earthquake preparation] (IFZ AN SSSR, M, 1984) 189 p. 